\title{
High and conventional rates of positive pressure ventilation
}

\author{
D FIELD, A D MILNER, AND I E HOPKIN
}

Department of Neonatal Medicine and Surgery, City Hospital, Nottingham

SUMmaRY We compared high frequency positive pressure ventilation with conventional rate ventilation in 23 preterm infants with the idiopathic respiratory distress syndrome. Nine infants (10 studies) were making spontaneous respiratory efforts during conventional ventilation that abated at 100 breaths per minute. Six of these showed an increase in $\mathrm{TcPo}_{2}$ of at least $10 \%$ at the higher rate (mean $18 \cdot 5 \%$ ). Two babies showed no change during high frequency positive pressure ventilation, and in one baby (the largest) the $\mathrm{TcPo}_{2}$ fell. Eight infants were apnoeic at both ventilator rates: five suffered a fall in $\mathrm{TcPo}_{2}$ of at least $10 \%$ at 100 breaths per minute (mean $19 \%$ ) and three were unchanged. A further six infants (seven studies) would not tolerate a reduction in rate from 100 breaths per minute without an increase in $\mathrm{F}_{\mathrm{I}} \mathrm{O}_{2}$. Failure to tolerate a conventional ventilator rate in these circumstances seemed related to the onset or a noticeable increase in spontaneous respiratory efforts.

In the past decade there have been a number of clinical trials designed to identify the optimum pattern of ventilation for the idiopathic respiratory distress syndrome. ${ }^{1-3}$ Recent publications have dealt, in particular, with the possible advantages of jet and oscillatory ventilation. ${ }^{4-7}$ In this country, however, most infants still receive the type of respiratory support suggested by Reynolds in $1975^{8}$ in a review publication based, to a large extent, on his earlier work. ${ }^{910}$ In addition, most units in this country do not use routine muscular paralysis for artificial ventilation. The recent work of Greenough et al ${ }^{11}$ showing the role of spontaneous respiration in the production of pneumothoraces has renewed interest in this subject.

We have devised a system that enables us to produce the optimum ventilation for our sickest preterm infants on an individual basis. Using this apparatus we are able to monitor simultaneously tidal exchange, ventilator pressure, the infants' respiratory efforts, and transcutaneous gas trends during a series of ventilator changes over a period of hours. In our initial work with this system we were impressed by the fact that some infants seemed to benefit from the use of ventilator rates in excess of 60 breaths per minute. In particular, the infants who improved seemed to be those making active respiratory efforts when ventilated at conventional rates, and these efforts ceased when the ventilator rate was increased. We have attempted to test this hypothesis more formally in the present study.

Ethical permission for this work was given by the North Nottingham Ethical Committee. Informed consent was given by parents.

\section{Subjects}

Twenty three infants were studied on 25 occasions over a nine month period. (Mean birthweight 1.45 $\mathrm{kg}$, range 0.68 to $2.4 \mathrm{~kg}$; gestational age 30 weeks, range 26 to 40 weeks). All babies had a clinical diagnosis of idiopathic respiratory distress syndrome, and at the time of study were in the acute stage of their illness, showing no tendency towards resolution. The infants' mean age at the time of study was 4 days, range 1 to 25 days. All babies were receiving respiratory support from a Draeger Babylog ventilator (time cycled pressure limited).

\section{Apparatus}

The following parameters were measured:

(1) Inflation pressure-a wide bore needle was inserted into the endotracheal tube at the point where it entered the mouth. The needle was connected to an SE Laboratory's 4.86 pressure transducer. Calibration was performed using a water monometer. 
(2) Oesophageal pressure-a $3 \mathrm{~cm}$ oesophageal balloon on a 6 FG catheter was passed into the lower portion of the oesophagus and connected to an SE Laboratory's 4.86 pressure transducer. Calibration was performed as above, but the balloon was positioned simply to produce the optimum signal so that the spontaneous respiratory efforts could be assessed.

(3) Tidal Volume-A Fleisch type 'o' pneumotachograph was positioned between the patient manifold of the ventilator circuit and the infant's endotracheal tube. A bias flow of 2 litres per minute was achieved by inserting a 21 gauge needle between the pneumotachograph and the endotracheal tube and connecting this to a suction pump (Diapump), producing a pressure drop of approximately $900 \mathrm{~cm}$ $\mathrm{H}_{2} \mathrm{O}$ across the needle. This ensured that the bias flow was not measurably affected by the ventilator cycling pressure. Equally, ventilator performance was not affected provided the ventilator circuit was compensated for the loss of the bias flow. Electronic integration of the flow signal allowed a volume trace to be obtained. Volume calibration was performed by injecting and withdrawing known volumes of air across the pneumotachograph.

The rise time of the SE Laboratory's pressure transducers, measured by bursting balloons in a bottle, was $6 \mathrm{msec}$. The rise time for the pneumotachograph and differential pressure transducer was $10.3 \mathrm{msec}$. The pneumotachograph was shown to respond in a linear fashion for flows up to 30 litres per minute when tested against a rotameter.

All signals were recorded on paper (Devices recorder) and retained on tape (Racal tape recorder). Analysis of ventilator pressure and volume signals, where not affected by spontaneous breaths, was made with the aid of a Commodore 4032 computer, using 30 seconds of consecutive breaths or at least 20 inflations. Where this was not possible, calculations were made by hand from the paper traces and were based on a similar number of breaths.

Transcutaneous blood gases were measured using a Radiometer transcutaneous $\mathrm{PO}_{2}$ and $\mathrm{PCO}_{2}$ system. If a Searle intra-arterial oxygen electrode was in situ at the time of study, this was used to measure $\mathrm{PaO}_{2}$. Transcutaneous values were verified using an arterial blood gas sample during each study and always showed close correlations (within 5\%).

\section{Methods}

Each baby was studied in his incubator and disturbance was limited to connection of the pneumotachograph and passage of the oesophageal balloon. Transcutaneous electrodes were attached to appropriate sites on the chest or abdomen, and then allowed to stabilise.

At each ventilator setting transcutaneous readings $\overrightarrow{\overrightarrow{\vec{F}}}$ were recorded at two minute intervals for at least $14 \stackrel{5}{7}$ minutes. If required, this period was extended until 등 readings were stable for at least six minutes. During $\frac{\bar{c}}{\mathrm{c}}$ the period of observation, pressure and volume $\vec{\sigma}$ signals were recorded, and if possible, fed via an $\cong$ analogue to digital converter for computer analysis. कै

An attempt was made to stabilise each infant at a $\overrightarrow{0}$ conventional ventilator rate (30 to 50 breaths per $\stackrel{-}{-}$ minute) and at a rate of 100 breaths per minute, $\vec{\omega}$ while leaving peak inspiratory pressure, positive end expiratory pressure, inspiratory to expiratory ratio, and $\mathrm{F}_{\mathrm{I}} \mathrm{O}_{2}$ the same. Six babies studied on seven ir occasions could not be stabilised at a conventional ventilator rate without increasing the $\mathrm{F}_{\mathrm{I}} \mathrm{O}_{2}$ : no $\overrightarrow{\mathrm{N}}$ measurements could be made, therefore, at the $\vec{\overrightarrow{ }}$ slower rate in these studies. No infant failed to $\vec{G}$ stabilise at 100 breaths per minute.

\section{Results}

We successfully studied 17 babies on a total of $18 \frac{\Phi}{3}$ occasions at both a conventional ventilator rate and a rate of 100 breaths per minute. Three patterns emerged based on the $\mathrm{TcPO}_{2}$ response. Six babif $\vec{\varnothing}$ studied on a total of seven occasions had a rise $\mathrm{TcPO}_{2}$ of at least $10 \%$ during rapid ventilation (mean $23.4 \%$, range 10 to $42 \%$ ). All of these infants had been making respiratory efforts at the lower rate of ventilation which stopped when the ventilator rate was increased to 100 breaths per minute.

Six babies, each studied on a single occasion, $\stackrel{\circ}{\Rightarrow}$ suffered a fall in $\mathrm{TcPO}_{2}$ of at least $10 \%$ during rapid ventilation (mean $21 \%$, range 13 to $36 \%$ ). Five of these babies made no respiratory efforts at either conventional ventilator rates or at 100 breaths per minute. The sixth baby was making respiratory efforts at the conventional ventilator rate but these? abated at 100 breaths per minute. This baby was the 3 largest of this group of 17 , with a birthweight of $2.3 \mathrm{~kg}$.

Five babies, each studied once, showed a change in $\mathrm{TcPo}_{2}$ of less than $1 \%$ (mean $-0.2 \%$, range $-1 \%$ 궁 to $+1 \%$ ). Two of these infants were breathing $\frac{D}{0}$ during conventional ventilation but this ceased at the rate of 100 breaths per minute. The remaining $N$ three studies were on infants who were apnoeic at both ventilator rates. Transcutaneous $\mathrm{TcPCO}_{2}$ fell at $\mathrm{N}$ the higher ventilator rate in all 18 studies (mean $\omega$ $11 \%$, range 3 to $24 \%$ ).

The details of tidal volume, minute volume, 0 $\mathrm{TcPo}_{2}$, and $\mathrm{TcPCO}_{2}$ are given in Tables 1 to 3. There $\mathbb{\complement}$ was no significant difference in the initial ventilator $?$ settings and $\mathrm{F}_{1} \mathrm{O}_{2}$ at the time of study between those 
Table 1 Results of babies with improved $\mathrm{TcPo}_{2}$ at high rate ventilation

\begin{tabular}{|c|c|c|c|c|c|c|c|c|c|}
\hline No of babies & No of studies & $\begin{array}{l}\text { Mean } \\
\text { rate } \\
\text { (per min) }\end{array}$ & $\begin{array}{l}\text { Spontaneous } \\
\text { respiration }\end{array}$ & $\begin{array}{l}\text { Mean } \\
\text { tidal volume } \\
\text { (ml) }\end{array}$ & $\begin{array}{l}\text { Mean } \\
\text { minute } \\
\text { volume }(\mathrm{ml})\end{array}$ & $\begin{array}{l}\text { Mean } \\
\mathrm{TcPo}_{2} \\
(\mathrm{mmHg})\end{array}$ & $\begin{array}{l}\text { Mean } \\
T_{c P c O_{2}} \\
(\mathrm{mmHg})\end{array}$ & $\begin{array}{l}\text { Mean } \\
F_{1} o_{2} \\
(\%)\end{array}$ & $\begin{array}{l}\text { Mean } \\
\text { ventilator } \\
\text { settings }\end{array}$ \\
\hline 6 & 7 & $\begin{array}{r}45 \\
100\end{array}$ & $\begin{array}{l}\text { Yes } \\
\text { No }\end{array}$ & $\begin{array}{l}8 \cdot 14 \\
7 \cdot 14\end{array}$ & $\begin{array}{l}332 \\
721\end{array}$ & $\begin{array}{l}44 \\
54\end{array}$ & $\begin{array}{l}50 \\
44\end{array}$ & 80 & $19 / 2$ \\
\hline
\end{tabular}

Table 2 Results of babies who showed no change in $\mathrm{TcPo}_{2}$ at high rate ventilation

\begin{tabular}{|c|c|c|c|c|c|c|c|c|c|}
\hline No of babies & No of studies & $\begin{array}{l}\text { Mean } \\
\text { rate } \\
\text { (per min) }\end{array}$ & $\begin{array}{l}\text { Spontaneous } \\
\text { respiration }\end{array}$ & $\begin{array}{l}\text { Mean } \\
\text { tidal volume } \\
(m l)\end{array}$ & $\begin{array}{l}\text { Mean } \\
\text { minute } \\
\text { volume }(\mathrm{ml})\end{array}$ & $\begin{array}{l}\text { Mean } \\
\mathrm{TcPo}_{2} \\
(\mathrm{mmHg})\end{array}$ & $\begin{array}{l}\text { Mean } \\
\mathrm{TcPco}_{2} \\
(\mathrm{mmHg})\end{array}$ & $\begin{array}{l}\text { Mean } \\
F_{1} o_{2} \\
(\%)\end{array}$ & $\begin{array}{l}\text { Mean } \\
\text { ventilator } \\
\text { settings }\end{array}$ \\
\hline \multirow{3}{*}{2} & & 40 & Yes & 7 & 222 & 61 & 49 & & \\
\hline & 2 & 100 & No & 5.9 & 555 & 60 & 44 & 68 & $21 / 3$ \\
\hline & & 40 & No & $12 \cdot 6$ & 475 & 56 & 38 & & \\
\hline 3 & 3 & 100 & No & 11 & 995 & 56 & 35 & 72 & $20 / 2$ \\
\hline
\end{tabular}

Table 3 Results of babies who showed a deterioration in $\mathrm{TcPo}_{2}$ at high rate ventilation

\begin{tabular}{|c|c|c|c|c|c|c|c|c|c|}
\hline No of babies & No of studies & $\begin{array}{l}\text { Mean } \\
\text { rate } \\
(\text { per min) }\end{array}$ & $\begin{array}{l}\text { Spontaneous } \\
\text { respiration }\end{array}$ & $\begin{array}{l}\text { Mean } \\
\text { tidal volume } \\
(\mathrm{ml})\end{array}$ & $\begin{array}{l}\text { Mean } \\
\text { minute } \\
\text { volume }(\mathrm{ml})\end{array}$ & $\begin{array}{l}\text { Mean } \\
\mathrm{TcPo}_{2} \\
(\mathrm{ml})\end{array}$ & $\begin{array}{l}\text { Mean } \\
\mathrm{TcPcO}_{2} \\
(\mathrm{mmHg})\end{array}$ & $\begin{array}{l}\text { Mean } \\
F_{1} O_{2} \\
(\%)\end{array}$ & $\begin{array}{l}\text { Mean } \\
\text { ventilator } \\
\text { settings }\end{array}$ \\
\hline \multirow{3}{*}{1} & & 30 & Yes & $15 \cdot 0$ & 420 & 102 & 69 & & \\
\hline & 1 & 100 & No & $12 \cdot 2$ & 1230 & 65 & 53 & 75 & $20 / 2$ \\
\hline & & 40 & No & 12.6 & 503 & 62 & 60 & & \\
\hline 5 & 5 & 100 & No & $9 \cdot 1$ & 872 & 50 & 55 & 68 & $18 / 2$ \\
\hline
\end{tabular}

who responded to high ventilator rates and those who did not (Student's $t$ test). Two babies who responded and two who did not had a pneumothorax at the time of study. Of the infants in the study group who subsequently died, two improved, one deteriorated, and one was unchanged at the high ventilator rates.

We had incomplete data on six more infants, studied on a total of seven occasions. All of these infants were initially ventilated at a rate of 100 breaths per minute and could not tolerate a reduction in this rate without an increase in $\mathrm{F}_{\mathrm{I}} \mathrm{O}_{2}$. In five of these studies the babies were initially apnoeic and on the other two occasions respiratory efforts were minimal, with a frequency less than $2 \%$ that of the ventilator. Each baby showed a rapid drop in $\mathrm{TcPo}_{2}$ which occurred as the ventilator rate was reduced. The deterioration coincided with the onset, or striking increase, in spontaneous respiration. The onset of active respiratory efforts did not seem to be related to a change in $\mathrm{TcPCO}_{2}$.

\section{Discussion}

Our findings support the hypothesis that for some infants receiving respiratory support a ventilator rate of 100 breaths per minute gives better oxygenation than a conventional rate; and further that this improvement is often related to the abatement of the infants' own respiratory efforts. For infants who are apnoeic at a conventional ventilator rate there seems to be no advantage from using a faster rate, and in some babies the $\mathrm{TcPo}_{2}$ may actually fall. These trends, however, do not seem to be absolute.

A previous study has shown a reduced incidence of pneumothorax in babies ventilated at 60 breaths per minute compared with a control group receiving ventilation at 20 to 40 breaths per minute. ${ }^{1}$ Greenough et al have reported an association between a particular pattern of spontaneous respiration occurring during ventilatory support and pneumothorax production. ${ }^{11}$ We have been able to correlate these two studies by showing a tendency for fast ventilator rates to cause spontaneous breathing to cease. This effect did not seem to be related to changes in $\mathrm{TcPCO}_{2}$.

The fall in $\mathrm{TcPo}_{2}$ in those infants who were apnoeic throughout the study is unexpected. We are currently looking at the effect of fast rate ventilation on mean airways pressure and tidal exchange, and to 
date have found both to be well maintained at rates of up to 100 breaths per minute. This is in contrast to the findings of Boros et al, using a different model of infant ventilator. ${ }^{2}$ One baby suffered a fall in $\mathrm{TcPo}_{2}$ with the cessation of spontaneous respiration. The trace indicated that this baby's respiratory efforts were sufficiently vigorous to make a positive contribution to ventilation at the slower rate.

We are unable to say from our present study how effective rapid rate ventilation may be in controlling pneumothorax production. This can only be formally tested in a randomised trial. During the past 12 months we have found it necessary to paralyse three babies receiving ventilation for idiopathic respiratory distress syndrome, while our current pneumothorax rate is approximately $26 \%$.

Within our unit fast rate ventilation is now used extensively and many babies are managed throughout the whole of their illness using rates of between 60 and 100 breaths per minute. We have found no short term problems relating to this pattern of ventilation, and improvement of oxygenation, if it occurs, is normally seen within 5 to 10 minutes.

Further studies are required to assess any change in the incidence of bronchopulmonary dysplasia in babies who receive high rate ventilation.

We thank medical and nursing staff for their patience, parents for permission to study their babies, and Mr L Ebrahim for financial help. This work was funded by an MRC grant.
References

${ }^{1}$ Heicher DA, Kasting DS, Harrod JR. Prospective clinical comparison of two methods for mechanical ventilation of neonates: rapid rate and short inspiratory time vs. slow rate and long inspiratory time. J Pediatr 1981;98:957-61.

2 Boros SJ, Campbell K. A comparison of the effects of high frequency-low tidal volume and low frequency-high tidal volume mechanical ventilation. J Pediatr 1980;97:108-12.

${ }^{3}$ Spahr RC, Klein AM, Brown DR, et al. Hyaline membrane disease. A controlled study of inspiratory to expiratory ratio in its management by ventilator. Am J Dis Child 1980;134:373-6.

4 Special Conference Report. High frequency ventilation for immature infants. Pediatrics 1983;71:280-7.

5 Frantz ID, Stark AR, Dorkin HL. Ventilation of infants at frequencies up to $1800 / \mathrm{min}$. Pediatr Res 1980;14:642.

6 Marchak BE, Thompson WK, Duffty P, et al. Treatment of RDS by high frequency oscillatory ventilation: a preliminary report. J Pediatr 1981;99:287-92.

7 Carlo WA, Chatburn RL, Martin RJ, et al. Decrease in airway pressure during high-frequency jet ventilation in infants with respiratory distress syndrome. J Pediatr 1984;1:101-7.

${ }^{8}$ Reynolds EO. Management of hyaline membrane disease. $\mathrm{Br}$ Med Bull 1975;31:18-24.

9 Herman S, Reynolds EOR. Methods for improving oxygenation in infants mechanically ventilated for hyaline membrane disease. Arch Dis Child 1973;48:612-7.

${ }^{10}$ Reynolds EOR. Effect of altering mechanical ventilator settings on pulmonary gas exchange in hyaline membrane disease. Arch Dis Child 1971;46:152-9.

11 Greenough A, Morley CJ, Wood S, Davis JA. Pancuronium prevents pneumothoraces in ventilated premature babies who actively expire against positive pressure inflation. Lance $1984 ; \mathbf{i}: 1-3$.

Correspondence to Dr D Field, Department of Neonatal Medicine City Hospital, Nottingham NG5 1PB.

Received 24 August 1984 